\title{
USEFULNESS OF NON-LEAD APRONS IN RADIATION PROTECTION FOR PHYSICIANS PERFORMING INTERVENTIONAL PROCEDURES
}

\author{
Masayuki Zuguchi ${ }^{1, *}$, Koichi Chida ${ }^{1}$, Masaaki Taura ${ }^{2}$, Yohei Inaba ${ }^{2}$, Ayako Ebata ${ }^{2}$ and Shogo Yamada ${ }^{3}$ \\ ${ }^{1}$ Course of Radiological Technology, Health Sciences, Tohoku University Graduate School of Medicine, \\ 2-1 Seiryo, Aoba, Sendai 980-8575, Japan \\ ${ }^{2}$ Department of Radiological Technology, School of Health Sciences, Faculty of Medicine, Tohoku \\ University, 2-1 Seiryo, Aoba, Sendai 980-8575, Japan \\ ${ }^{3}$ Department of Radiology, Tohoku University Graduate School of Medicine, 1-1 Seiryo, Aoba, \\ Sendai 980-8574, Japan
}

Received April 24 2008, revised August 21 2008, accepted August 232008

\begin{abstract}
At present, interventional radiology (IVR) tends to involve long procedures (long radiation duration), and physicians are near to the source of scattered radiation. Hence, shielding is critical in protecting physicians from radiation. Protective aprons and additional lead-shielding devices, such as tableside lead drapes, are important means of protecting the physician from scattered radiation. The purpose of this study was to evaluate whether non-lead aprons are effective in protecting physicians from radiation during IVR procedures. In this study, the radiation protection effects of commercially available protective lead and non-lead aprons, when exposed to diagnostic $X$ rays, are compared. The performance of these non-lead and lead aprons was similar for scattered X rays at tube voltages of $60-120 \mathrm{kV}$. Properly designed non-lead aprons are thus more suitable for physicians because they weigh $\sim 20 \%$ less than the lead aprons, and are non-toxic.
\end{abstract}

\section{INTRODUCTION}

Although the wide acceptance of interventional radiology (IVR) procedures has led to increasing numbers of interventions being performed, the radiation doses from IVR are higher than those for other commonly performed general X-ray examinations ${ }^{(1,2)}$. At present, IVR procedures tend to be complex, which increases the fluoroscopy time, and therefore the doses to both the physician and patient $^{(3-5)}$. Furthermore, as most physicians stand close to the patient, the dose received from direct and scattered radiation is higher. Therefore, radiation protection for physicians during IVR poses a very important problem, and the physician must wear a protective apron ${ }^{(6-10)}$. However, conventional protective aprons are heavy as they are made of lead, so the physician may not tolerate wearing one for long procedures. Recently, non-lead protective aprons made of lighter weight, composite materials have been developed ${ }^{(11)}$.

This fundamental study compares the radiationshielding effects of non-lead and lead aprons to evaluate whether non-lead aprons are effective in protecting physicians from radiation during IVR procedures.

*Corresponding author: zuguchi@wm.pdx.ne.jp

\section{MATERIALS AND METHODS}

Conventional lead $(\mathrm{Pb})$ aprons of 0.25-, 0.35- and $0.475-\mathrm{mm}$ thickness and non-lead aprons with 0.25 -, 0.35 - and $0.475-\mathrm{mm} \mathrm{Pb}$ equivalents were studied (KYOKO, Japan). Since non-lead aprons consist of composite materials, mainly $\mathrm{W}$ and $\mathrm{Sn}$, they are $\sim 20 \%$ lighter than lead aprons ${ }^{(12)}$. Diagnostic X-ray equipment (model UD-150; maximum tube potential: $140 \mathrm{kVp}$; Shimadzu, Japan) was used. The shielding effect (in \%) of each apron is determined as follows:

$$
\begin{aligned}
\text { Shielding effect }= & \frac{\begin{array}{l}
\text { no }- \text { apron measurement } \\
\text { no }- \text { apron measurement }
\end{array}}{} \\
& \times 100 .
\end{aligned}
$$

The protective effect $(\%)$ of the non-lead aprons compared with the lead aprons is determined as follows:

$$
\begin{aligned}
& \text { Protective effect of non-lead aprons } \\
& =\frac{\text { shielding effect of non-lead apron }}{\text { shielding effect of lead apron }} \times 100 \text {. }
\end{aligned}
$$




\section{Direct $X$ rays}

Figure 1 shows a schematic of the method used for the measurement of dose, using a $60-\mathrm{ml}$ ionisation chamber (energy range: $25 \mathrm{keV}$ to $1 \mathrm{MeV}$; 9015 dosemeter; RadCal, USA) for direct $\mathrm{X}$ rays (general exposure) with and without an apron. The X-ray conditions were as follows: tube potential $60,70,80$, $90,100,110$ and $120 \mathrm{kV}$; tube current $160 \mathrm{~mA}$; exposure time $0.5 \mathrm{~s}$ and exposure area in the apron $13 \times 13 \mathrm{~cm}$.

\section{Scattered X rays}

Figure 2 shows a schematic of the dose measurement method used for the measurement of the effect of scattered X rays (fluoroscopy) with and without an apron. The measurements were performed using a 20 -cm-thick acrylic phantom $(30 \times 30 \mathrm{~cm})$ positioned at $100 \mathrm{~cm}$ from the $\mathrm{X}$-ray machine to produce scattered $X$ rays similar to what the patient would produce. An ionisation chamber survey meter (ICS321; ALOKA, Japan) was positioned at $45 \mathrm{~cm}$ from the phantom to measure the scattered radiation. The $\mathrm{X}$-ray conditions were as follows: tube potential 60 ,

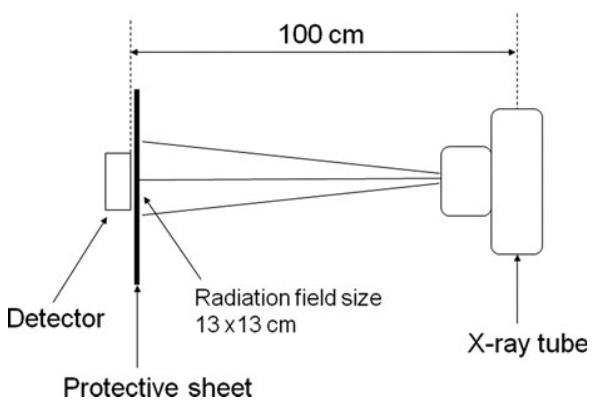

Figure 1. Schematic of the dose measurement method used for direct $\mathrm{X}$ rays (general exposure) without and with a radiation protective apron.
80,100 and $120 \mathrm{kV}$; tube current $1 \mathrm{~mA}$ (continuous); exposure area (radiation field size) in the entrance acrylic phantom $30 \times 30 \mathrm{~cm}$.

\section{RESULTS}

\section{Direct $\mathrm{X}$ rays}

Figure $3 \mathrm{a}-\mathrm{c}$ shows the shielding effect of each apron from direct $X$ rays. As the tube voltage increased, the shielding effects of both types of apron decreased. Figure 4 shows that the protective effects of the non-lead aprons for direct $\mathrm{X}$ rays were essentially uniform from 60 to $100 \mathrm{kV}$, and decreased somewhat over $100 \mathrm{kV}$; an $\sim 4 \%$ decrease was observed in the non-lead $0.35-\mathrm{mm} \mathrm{Pb}$ equivalent apron at $120 \mathrm{kV}$. The protective effect of the nonlead $0.25-\mathrm{mm} \mathrm{Pb}$ equivalent apron was somewhat lower than that of the others.

\section{Scattered $X$ rays}

Figures $5 \mathrm{a}-\mathrm{c}$ shows the shielding effect of each apron from scattered $\mathrm{X}$ rays. As the tube voltage increased, the shielding effect decreased for both aprons. Figure 6 shows that the protective effects of the non-lead aprons for scattered $\mathrm{X}$ rays were essentially uniform from 60 to $120 \mathrm{kV}$. The protective effect of the non-lead $0.25-\mathrm{mm} \mathrm{Pb}$ equivalent apron was somewhat lower $(\sim 98 \%)$ than that of the others $(>99 \%)$.

The largest coefficient of variation $(\mathrm{CV})$ in all the figures was $0.2 \%$; the stability of the measured dose in this study was excellent.

\section{DISCUSSION}

The three-point policy of external radiation protection for staff is: reduce the exposure time, increase the distance from the radiation source and use radiation shielding. Non-lead aprons allow the physicians to conform to the later policy, while providing

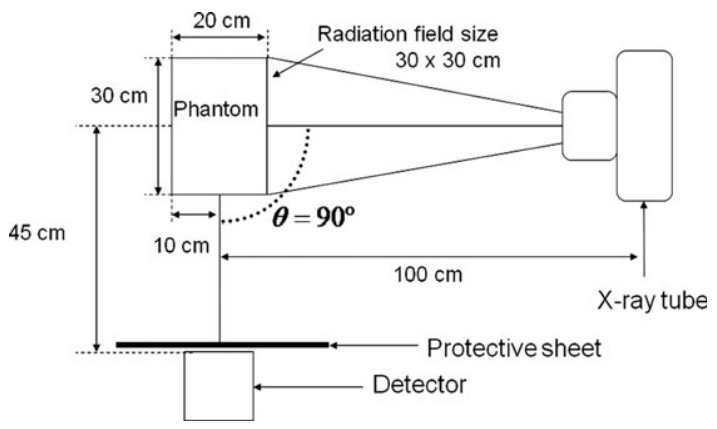

Figure 2. Schematic of the dose measurement method used for scattered X rays (fluoroscopy) without and with a radiation protective apron. 
USEFULNESS OF NON-LEAD APRONS
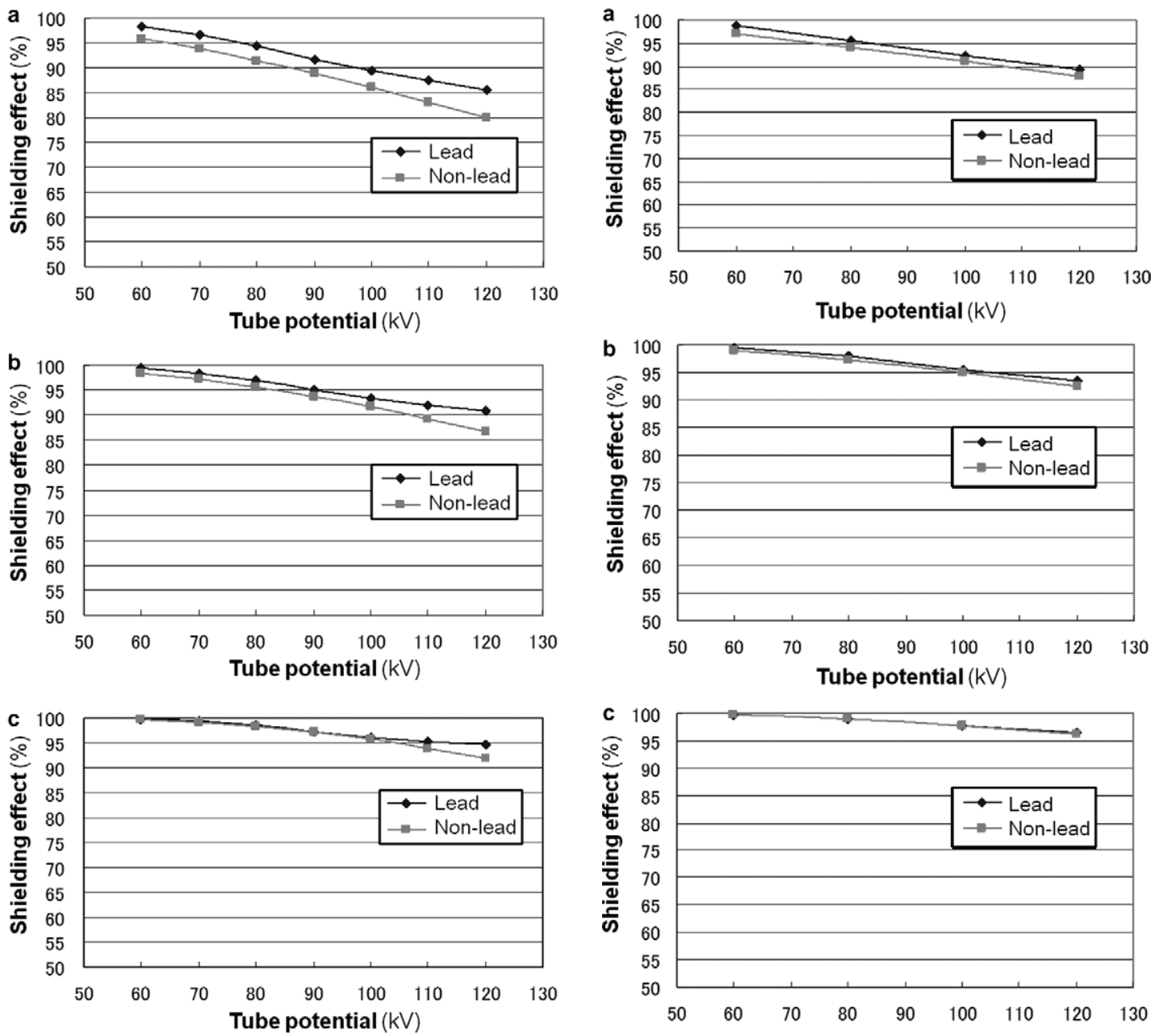

Figure 3. Shielding effect in terms of X-ray transmission of non-lead and lead aprons against direct $X$ rays. (a) 0.25 $\mathrm{mm} \mathrm{Pb}$ equivalent, (b) $0.35-\mathrm{mm} \mathrm{Pb}$ equivalent and (c) $0.475-\mathrm{mm} \mathrm{Pb}$ equivalent.

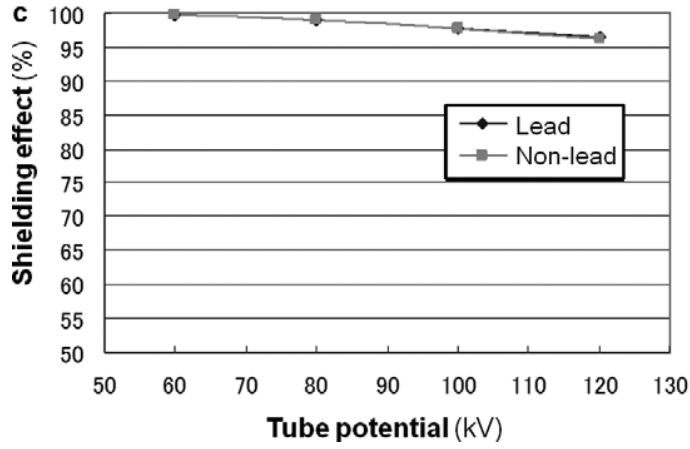

Figure 5. Shielding effect in terms of X-ray transmission of non-lead and lead aprons against direct $X$ rays. (a) 0.25 $\mathrm{mm} \mathrm{Pb}$ equivalent, (b) $0.35-\mathrm{mm} \mathrm{Pb}$ equivalent and (c) $0.475-\mathrm{mm} \mathrm{Pb}$ equivalent.

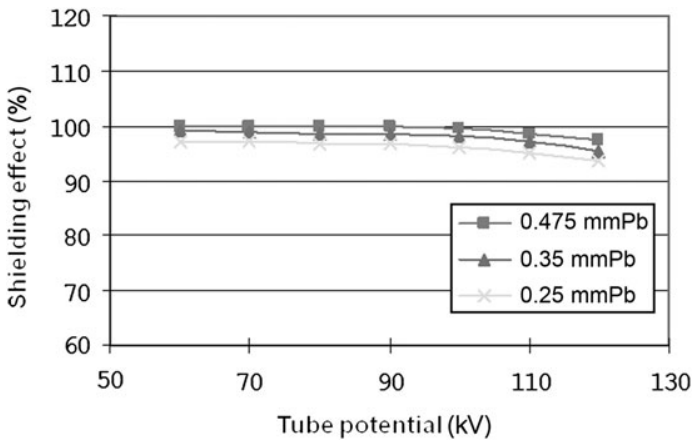

Figure 4. Shielding effect in terms of X-ray transmission of the non-lead apron against direct $X$ rays.

more comfort and avoiding disposal costs associated with toxic lead.

For direct $\mathrm{X}$ rays, the shielding effect of the lead apron was superior to that of non-lead aprons at over $100 \mathrm{kV}$. Since the K-absorption edge of lead is higher than that of the non-lead material, the shielding effect of the lead apron increases at higher X-ray energies $(>100 \mathrm{kV})$. In contrast, for scattered $\mathrm{X}$ rays, the shielding effects of lead and non-lead aprons are similar; consequently, the protective effects were essentially uniform from 60 to $120 \mathrm{kV}$ (even when over $100 \mathrm{kV}$ ). This is because the energy of scattered $\mathrm{X}$ rays is lower than that of direct $\mathrm{X}$ rays at the same tube voltage, so the $\mathrm{K}$-absorption 


\section{ZUGUCHI ET AL.}

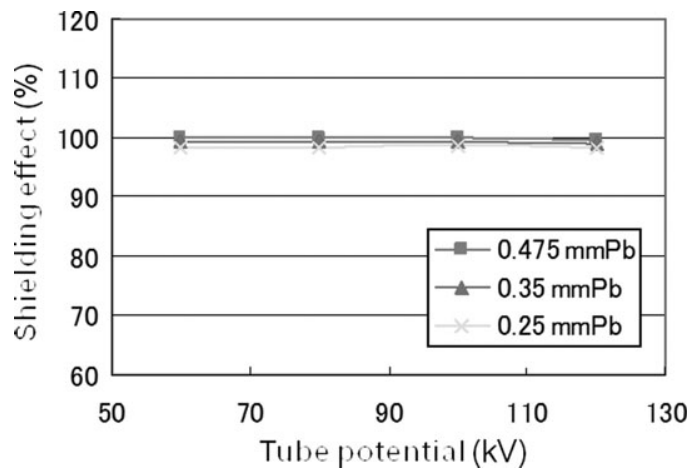

Figure 6. Shielding effect in terms of X-ray transmission of the non-lead apron against scattered $\mathrm{X}$ rays.

edge of lead cannot be used; hence, for scattered $\mathrm{X}$ rays, the shielding effect of a lead apron is similar to that of a non-lead apron.

As non-lead aprons are non-toxic and weigh less than lead aprons, and IVR staff mainly receive doses from scattered $\mathrm{X}$ rays, non-lead aprons should be the preferred apron for the radiation protection of IVR staff, especially physicians.

\section{CONCLUSION}

Here, the radiation protection provided by lead and non-lead aprons against diagnostic X-ray energies are compared. For direct X rays, non-lead aprons provided similar attenuation to lead aprons (within $2 \%$ in $0.35-\mathrm{mm} \mathrm{Pb}$ equivalents), although at tube voltages over $100 \mathrm{kV}$, the protection provided by non-lead aprons was somewhat lower $(\sim 4 \%$ decrease in the non-lead $0.35-\mathrm{mm} \mathrm{Pb}$ equivalent apron at $120 \mathrm{kV}$ ). For scattered $\mathrm{X}$ rays, the protection provided by non-lead and lead aprons was similar (within $1 \%$ in $0.35-\mathrm{mm} \mathrm{Pb}$ equivalents) at tube voltages of 60 to $120 \mathrm{kV}$. Therefore, as the radiation that most physicians are exposed to consists of scattered $\mathrm{X}$ rays, non-lead aprons provide sufficient protection. Since non-lead aprons weigh less than lead aprons, non-lead aprons are more suitable in providing radiation protection for physicians.

\section{FUNDING}

This work was supported in part by a Grant-in-Aid for Scientific Research (19591398) from the Japan Society for the Promotion of Science.

\section{ACKNOWLEDGEMENTS}

The authors thank Mrs Tomoko Sasaki for secretarial work. Thanks are also given to Mr Hirotaka
Shimura, Mr Daisuke Ito, from the Department of Radiology, Tohoku University Hospital, for helpful advice regarding the technical analysis.

\section{REFERENCES}

1. International Commission on Radiological Protection. ICRP Publication 85: avoidance of radiation injuries from medical interventional procedures. Ann ICRP 2001;30/2: Publication 85. (2001).

2. Chida, K., Kagaya, Y., Saito, H., Takai, Y., Takahashi, S., Yamada, S., Kohzuki, M. and Zuguchi, M. Total entrance skin dose: an effective indicator of maximum radiation dose to the skin during percutaneous coronary intervention. Am. J. Roentgenol. 189(4), W224-7 (2007).

3. Vano, E., Gonzalez, L. and Beneytez, F. Lens injuries induced by occupational exposure in non-optimized interventional radiology laboratories. Br. J. Radiol. 71(847), 728-733 (1998).

4. Hirshfeld, J. W., Balter, S. and Brinker, J. A. ACCF/ AHA/HRS/SCAI clinical competence statement on physician knowledge to optimize patient safety and image quality in fluoroscopically guided invasive cardiovascular procedures. A report of the American college of cardiology foundation/American heart association. American college of physicians task force on clinical competence and training. Circulation 111, 511-532 (2005).

5. Tsapaki, V., Kottou, S., Vano, E., Parviainen, T., Padovani, R., Dowling, A., Molfetas, M. and Neofotistou, V. Correlation of patient and staff doses in interventional cardiology. Radiat. Prot. Dosim. 117, 26-29 (2005).

6. Balter, S. Stray radiation in the cardiac catheterisation laboratory. Radiat. Prot. Dosim. 94(2), 183-188 (2001).

7. Kuon, E., Schmitt, M. and Dahm, J. B. Significant reduction of radiation exposure to operator and staff during cardiac interventions by analysis of radiation leakage and improved lead shielding. Am. J. Cardiol. 89(1), 44-49 (2002).

8. Chida, K., Morishima, Y., Katahira, Y., Chiba, H. and Zuguchi, M. Evaluation of additional lead shielding in protecting the physician from radiation during cardiac interventional procedures. Nippon Hoshasen Gijutsu Gakkai Zasshi. 61(12), 1632-1637 (2005).

9. Siiskonen, T., Tapiovaara, M., Kosunen, A., Lehtinen, M. and Vartiainen, E. Occupational radiation doses in interventional radiology: simulations. Radiat. Prot. Dosim. 129(1-3), 36-38 (2008).

10. Schultz, F. W. and Zoetelief, J. Dosemeter readings and effective dose to the cardiologist with protective clothing in a simulated interventional procedure. Radiat. Prot. Dosim. 129(1-3), 311-315 (2008).

11. Yaffe, M. J., Mawdsley, G. E., Lilley, M., Servant, R. and Reh, G. Composite materials for x-ray protection. Health Phys. 60(5), 661-664 (1991).

12. Aoki, Y. Protective apron using composite materials. Kyokko X-ray 30, 22-32 (1993) (in Japanese). 